\title{
An Artistic Analysis of The Force That Through the Green Fuse
}

\author{
LIU Juan \\ Leshan Normal University, Leshan, China
}

\begin{abstract}
In this paper, by minutely analyzing the elements of the poems and the poetic devices employed, the author will endeavor to explore those elements of and the poetic devices used in The Force That Through the Green Fuse by Dylan Thomas, a great Welsh modern poet, to interpret how those elements and poetical devices work together to bring the general readership home and how tragically fragile and transitory human life and natural beings are in the face of death.
\end{abstract}

Keywords: Dylan Thomas, The Force That Through the Green Fuse, Artistic Analysis

\section{Introduction}

Poetry, the most condensed and concentrated form of literature, resorts to multidimensional language for conveying the meaning and expressing emotions. As critic Perrine pointed out in his book, "Poetry achieves its extra dimensions by drawing more fully and more consistently than ordinary language on a number of language resources, among which are imagery, rhythm, form, diction, imagery, paradox, metaphor, symbol, etc.” (Perrine, 1987, p. 10). These language resources are poetry's elements and devices which are often efficiently organized as a tree in a successful poetry. The Force That Through the Green Fuse is an organism whose every element serves to reinforce the theme and cooperate with every part to preserve and express the life that within it. This paper will demonstrate to the reader how these poetic elements and poetical devices work together to make this poem sucessful and unique.

\section{Theme}

The Force That Through the Green Fuse ${ }^{1}$ is a highly metaphorical and deeply addressing poem. It is through time that flowers grow and age and water are driven. But in the end, it "destroys" each living thing; or rather each living thing is "destroyed" within it and through it. The entire passionate and positive connotation in this poem is calmly countered with the single ending - death. Even the act of creating new life is another gesture towards a certain doom, because all the while the force that propels all of this grandness is a destroyer rather than a creator. In this ambivalence, we become aware of the contradictions and thus realize what the poem is trying to convey. By depicting the power or effect of time on human existence and nature, it exhibits the theme of death, time, and the tragically fragile and transitory nature of human life and the nature.

LIU Juan, lecturer, M.A., School of Foreign Languages, Leshan Normal University.

1 The poem The Force That Through the Green Fuse in this paper is quoted from The Poems of Dylan Thomas (p. 90). (2003). 


\section{Voice}

The first person speaker "I" addresses to us directly which makes the aesthetic distance so short that we are like the intimate friends of the speaker listening to his interior monologue. The persona constantly reiterates his dismay that a force that brings life vitality and beauty is also responsible for aging and death. This poem reveals a dialectical truth that all things, no matter how prosperous they are, must die. It is exactly this paradox that stands as the mystery of life and depresses the speaker. If there is an initial beauty in life, it cannot help but move to death and it is this realization that makes us feel as if there is no security or meaning, or at least a way of controlling life, that drives the persona to meditate on the nature of death. Thus, through the description by the speaker who would take death as an end rather than a transition, the poet's attitude towards his subject matter in this poem is quite pessimistic. So to sum up the above analysis, the tone in this poem is commiserating, dismal, and pessimistic.

\section{Title}

The title of this poem is well-chosen by the poet for it attracts not only the reader's interest of reading but also provokes the reader to meditate and speculate. Normally, the title tells us the main idea, the background, or even directly the theme of a poem. While the title of this poem, seemingly randomly taken from the first line of the first stanza, it prolongs our aesthetic process of reading for its ambiguity at the first sight. What puzzles us most are the meaning of the force and the meaning of the fuse. What on earth the force is? Is it destructive or constructive? What does the fuse refer to? Our reader's schemata of knowledge has been confronted by the estranged language usage, because we know that the color of fuse can be any color but green. Why is the fuse green? Those questions generated in the process of reading drives us readers read on to figure out the meaning of the green fuse. It is attractive and thought-provoking.

\section{Imagery}

This poem is primarily about death and the unity of life and death, but the poet tells us none of these things directly. He does not even use the words life and death, instead, he throws us upon piles of mental pictures about death. This poem is heavily loaded with a lot of images, perceptual and intellectual. It is insensible and troublesome to categorize these images according to different senses, because images in this poem often appeal to more than one sense. What is more, the images in each stanza are so closely connected with each other, which resist any awkward categorization. And a tuning point can be spotted by a careful reader in stanza four. For the sake of explicitness and convenience, I will analyze imagery in this poem stanza by stanza.

In the first stanza, the word "fuse" immediately presents us a pictorial image that "a slim cord or a piece of string which is lit to make a bomb or a fire worker to explode"2 to carry a flame along its length to detonate an explosive at the other "end". The idea conveyed is that the "force" is quite powerful and is to cause an explosion. However, the color "green" assigned to "fuse" is unique. It resembles the bud stem where flower takes its shape and blossoms. The hidden explosive force is brought to life. "Drives" is another word so powerful that it makes us easily link "the force that drives the flower" to the kinesthetic image of a fuse driving

${ }^{2}$ Advanced learners' English-Chinese dictionary (p. 714). (2009). 
a fire through to become an explosion at the other end. Likewise, the shape and position of the bud of a flower arouse our imagination that the force through the green stem drives the bud at the top of the stem to fully blossom. "Drives my green age" reminds us that the teenagers grow up with energy and vigor. These two images, by appealing to our visual sense and sensation of movement, give us a vivid picture of creation and growing. In contrast, "blasts the roots of trees" gives us a kinesthetic image of destruction; we can see the destructive power obliterating trees by their roots. By "crooked rose", we can see the withering rose with dry petals and we even sense the unpleasant smell of a withered, stale rose. "Wintry fever" triggers our thermal sense (tactile) by conveying the coldness of winter and heat of a fever. All of the images in the first stanza can be divided into the destructive and creative ones. They are juxtaposed and contrasted in this stanza to imply the power or effect of time on nature and human existence.

In the second stanza, images of creation ("water through rocks", "red blood”) are associated with movement, vitality, and source of life, repeated in the verb "drives", before showing its antithesis in images of dryness and stagnation (“dries the mouthing steam”, "turns mine to wax"). More interestingly, the words "water" and "blood” seem interchangeable because the force that propels them is one and the same. This fact gives rise to the images of the streams and rivers acting as the "veins" of the earth, water representing the life source or "blood" of the earth. This makes the red blood and the veins of the following lines a kind of representational human imitation of it. The dynamic imagery and the static imagery in one sentence leave us a deep impression of the driving function and drying function of time. The last sentence "how at the mountain spring the same mouth sucks" (see Appendix) in this stanza conveys a frightening image. The negative images surpass positive ones so much that it conveys the mood far from cheerful and positive.

In the third stanza, the water whirl is whirled; the quicksand is stirred; and the blowing wind is roped. All of these portray a picture of chaos and violence. My shroud sail creates a ghost-ship-like concept which is unforeseen, mysterious, and horrible. If we combine this image with the whirlpool and blowing wind, we get a vivid picture of danger and an atmosphere of dismay-a ship with sails, sailing on a water surface, is destroyed by the whirlpool and the blowing wind only with its sails floating on the water. The sails become the shroud of the sunken ship and people. The second sentence is again an imagery of death, echoing the final sentence in stanza one and two. So the tone conveyed this time is more mysterious and morose than that of the previous stanzas.

In the forth stanza, the image of the sucking mouth in the second stanza becomes far more concrete by "lips". The verb "leech" is a more slow and gradual kinesthetic image than "suck", but sometimes more vicious and fatal. Love has been often regarded as an antidote or way of overcoming death and transcending time. But here it can only "calm her sores" instead of curing the wounds. It reinforce the idea that time can not be stopped. "Time has ticked a heaven round the stars" (see Appendix) is otherwise a image carrying a neutral and even positive quality, which serves as the contrast of the preceding stanzas and the following stanza to strengthen the theme.

In the fifth stanza, the "tomb”, "sheet”, and "crooked worm” all convey the death image, and thus emphasize the theme of death in the poem.

It is through the synthesis of the positive and negative imagery that the central theme of the death and time is brought out and tragically fragile and transitory nature of both nature and human life are projected. 


\section{Figures of Speech}

\section{Paradox}

Paradox is an important rhetoric device adopted in this poem. The most conspicuous one is "I am dumb to tell” (see Appendix). "Dumb to tell” is an apparent contradiction which sounds strange and absurd yet true. It is through the collocation of the two seemingly contradictory words that the speaker's complicated emotional feeling is conveyed.

The first sentence of stanza one is paradoxical. "The force through the green fuse drives the flower drives my green age" (see Appendix) suggests that the force here is creative and it is the motivational factor for the growth of flower and people. However, the following sentence "that blasts the roots of trees is my destroyer" (see Appendix) clearly shows that the force is destructive. How can a creative force at the same time be a destructive one? It seems inconceivable and self contradictory. But, with a second thought, we find it a yielding truth which is more interesting than everyday usage of language. Dialectically, a thing living in the world is simultaneously on the way to extinction - it is a philosophical truth. Plants are doomed to wither at the very time they shoot up; people are destined to die on the very day they are born; everything is doomed to be destroyed at the moment they are created. Destruction is aligned with destruction and the creation and destruction are part of the same process both for man and for nature.

The first sentence of stanza two also depicts the features of the force paradoxically as "the force that drives the water through the rocks drives my red blood; that drives the mouthing steams turns mine to wax" (see Appendix). Can the force making the water through the rocks dry the streams? Can the force making my pulse beat stop the vein pulsing? The same force that erodes the rocks away is in me and in my blood; the force that dries the generative streams dries my blood and ages me. In this sense, the natural force that brings about life and death is one; and the two natural processes are a unity as well.

Oxymoron deserves to be mentioned here, although it only appears once in the poem. "Wintry fever”,"the paradoxical utterance conjoins two terms that in ordinary usage are contraries” (Abrams, 2004, p. 201) conjoins two contradictory terms in the conventional sense yet it strikes us most. It combines a feeling of coldness and hotness together, which transcends human sense and logic. But it is so fresh and forceful that any kind of force can not match with the force of the combination of the two. Hence, the weirdness, mysteriousness, and the power of the force are vividly conveyed by this oxymoron.

In a word, the whole poem is full of paradoxical sayings in order to bring the central paradoxical and dialectical theme- the driving and steady force is the backdrop and setting for all things to occur.

\section{Metaphor}

A number of metaphors can be found in this poem, especially the metaphorical references to time. Time has been compared to the abstract "force" through the green fuse. This metaphor is so fresh that both the strong, creative, and destructive features of time are vividly depicted in one utterance, which also implies the unity of creation and destruction. "Wintry fever" and the sucking “mouth" are another two metaphorical expressions of time. "Wintry fever" puts the dreadful and eerie quality on time while the sucking mouth makes time imbued with the vampiric quality as it sucks life away. The hand is a metaphor for time as well. The shroud sail is a metaphor for death. The sail of the boat is a shroud which means the wrapping cloth of a dead body, and shows the 
inevitable journey to death that all life leads to.

\section{Symbol}

This poem is mainly concerned with the theme that the process of living growing is the process of dying. Nevertheless, we cannot find any direct words such as birth, growth, dead, kill, and so on. The poet applies a set of symbols to conveying a vivid and coherent imagery. For example, water is a symbol for life, and lime and rocks are symbols for death. These symbols combine and work together to show the unity of life and death.

Stanza two reminds us something quite interesting. Since water in streams is usually the symbol of people’s life. That "the force" sucks the water from the streams and the blood from the speaker "veins" really symbolizes people's condition in the western world where people do everything faster and faster for fear of wasting time. However, they are at last rewarded nothing but age and death.

\section{Allusion}

The biblical allusion to human being made from clay ("How of my clay is made the hangman's lime”) and the death image if hanging man shows that the source of life already contains the seeds of death.

Fallen blood “calming sores” is a biblical allusion which contains an obvious significance. As Ralph Maud said: "Loss of blood, in keeping with archaic lore, is beneficial. The refrain of this stanza makes the same assertion of unexpected good coming from evil” (Maud, 1963, p. 70). Indeed the concept of sacrifice is directly connected to this and the Christian undertone here is quite observable: When the lips of time leech the water from the fountain head, death is upon us, but remembering the "fallen blood" of Christ, we are supposedly redeemed and forgiven by our sins.

\section{Diction (Choice of Words, Choice of Details)}

The words and details are carefully chosen in this poem and are in concordance with the theme. In the first stanza, the words "green” and "drive” indicate the creativeness of the force. Whereas, "fuse” and "blast” are chosen to create a kind of explosive imagery to show the violent and destructive force of time. Juxtaposition and contrast are vividly displayed here. In the second stanza, water in the mouthing streams and red blood in the veins share so many similarities. Water and blood are both liquid elements; streams extend over the earth; and the veins spread all over the human body. Both of the water and blood can be sucked. This analogical detail conveys the kinship between human beings and nature. The four verbs “whirls, stirs, ropes and hauls” in the third stanza connote the violence and destructive force of time, and build up a horrific and mysterious atmosphere. Most details in those three stanzas are connected with death.

By contrast, the details in the forth stanza are mainly details with love and macrocosmic cycle. But the two seemingly irrelevant details contribute a lot to the reinforcement of the theme. The word clam not only serves as a solace for the scores of love, but also, together with the conjunctive word but (used here to show the contrast and difference), calms the negative tone. At the same time, the first-person possessive here becomes third-person, and as the poem retracts from the personal grief or grotesque tragedy of the "protagonist" a different view of time and death. Nevertheless, this kind of gentle and peaceful tone is not the basic one, and it serves as the foreshadowing of the final couplet. In the final stanza, that lover has been in the tomb shows that love, as the solace for scores in fourth stanza, cannot escape time and death eventually. Time still manages to destroy all even the pure and beautiful love. In a single stroke, the poet brings the reader back to the reality of the poem; the 
concept of death is reintroduced and reinforced. The word round in the final line of the fourth stanza shows that the universe is in a cycle and ticks imply that the cycling process is continues and unchanging. The whole universe is a macrocosm and always in the process of cycling like a clock. Here, the tone seems neutral and light, but it connotes a contrast to the mortal life of those micro beings such as man, plants, and geological ones described in the previous three stanzas and at the same time sets off and reinforce the commiserative and pessimistic tone.

\section{Form}

\section{Refrain}

The highly interesting refrain is that the word "mouth" is repeated three times in the second stanza. "Mouthing streams" of the second line and the "mouth sucks" at the mountain spring together suggest a picture of the estuary. Time commands the estuary to suck down the whole course of the stream into the sea. That time pushes the water into the sea is like nothing but pulling life towards death here.

"Same" occurs three times in the final line of the first, second, and the fifth stanza respectively. It means the force which creates and destroys the man does the same to the nature. It suggests that man and the nature are so closely with each other that both of them are the creature of the force and the victims of the force at last. "Same" reinforces kinship between man and nature and the same destiny they are heading for.

But the most important refrain, which is repeated throughout the whole poem, is of course the phrase "And I am dumb to tell...” (see Appendix). It emphasizes the speaker's or man's helplessness and even hopelessness in the face of time's unstoppable and incomprehensible power. In each case, the speaker is "dumb to tell” something or someone of time's effect on everything. This is because each of the things he addresses in the refrain has already witnessed time's powerful and destructive force and they do not need to be told of it: The crooked rose has been "bent" by time; the speaker's veins have experienced it because their blood has been turned to wax; the hanging man certainly knows its strength because he exists in its cycle; and a weather's wind need not be told of time's power, since it is itself a representation of it in the context. In a word, the repetition of "I am dumb to tell" plays a central role in keeping the consistence of the meaning and the tone of this poem. By appearing in the final sentence of each stanza, it also makes the poem an organic whole.

\section{The Length of the Line}

The third line of every stanza is shorter than other lines. The change in length helps to emphasize the line's power. The first instance is "is my destroyer" in the first stanza. It underlines that man, without exception, is also doomed to the same fate-death like nature. "Turns mine to wax" and "hauls my shroud" have the same function as the first one. But "shall calm her scores" emphasizes another point, which I have mentioned in the analysis of diction.

Another one deserving to be discussed here is that the last stanza only consists of two lines for the sake of emphasis. Our attention is certainly attracted by the couplet because the initial four stanzas all consist of five lines even without any in length. It is more like a summary of the whole poetry. Any questions, uncertainties, and ambiguities of the idea and the theme created by the previous stanzas can be clarified by the couplet. Without the couplet, we can not find the central tone of this poem because the fourth stanza has a neutral tone and is somewhat misleading. Bearing upon the basic tone, the final couplet serves as a reinforcement of the theme. 


\section{Sound}

The rhythm of this poem is iambic pentameter. "Iambic meters can be thoughtful and recollective, since they move from the uncertainty of an unstressed syllable to the certainty of a stressed one” (Gill, 1985, p. 36). The serious and slow rhythms in this poem solidify the emotional weight of what is being said and enact the commiserative and melancholy tone. The marching iambic rhythm, which characterizes the depicted events as certain, strong ,and unquestionable, also establishes a tone of inevitability.

We should shut up our mouth to pronounce the consonant sounds [m] in the end of "am" "dumb". The air is stopped by the closed two lips. It indicates that the speaker wants to speak his insight but is unable to express his emotion. We can not pronounce "am dumb" quickly. The sounds are both slow and grave in accordance with the dismal tone. In the final couplet, consonant [m] is repeated five times in "am dumb tomb same worm". The predominating consonant emphasizes the grief and tragedy of the "protagonist", like a mourning or passive acceptance death.

Another phonetic element that should be noted is the fact that the words "drives" and "dries", though used as opposing elements in the poem, are very alike in sound since [dr] is alliterated in the two words. The alliteration emphasizes the point that the destructive and creative forces are one and the same. It is also interesting to notice that the words "streams" and "sucks" create a type of slant rhyme; it invites the reader, in a way, to explore their possible hidden meanings.

In the first line of the fourth stanza, alliteration [1] in lips and leech shows that the action of sucking in the second stanza has seemingly been softened and slowed here. Consonant sound[s] repeated in lips, drips, gathers and sores in this line also reflect that the passing of time and life is smooth and stealthy without being perceived.

"Ticked" with its playful onomatopoeia, gives us a vivid impression that the whole universe is driving the time cycle by cycle.

\section{Conclusion}

By a close artistic analysis of The Force That Through the Green Fuse from eight poetry elements-theme, voice, title, imagery, figures of speech, diction, form, and sound, a comprehensive and clear conclusion could be come into that this poem fully displays how every single poetry elements and elements work together to form and organize a successful poem and how every element serves to strengthen the theme and make the poem full of energy.

\section{References}

Abrams, M. H. A. (2004). Glossary of literary terms (p. 201). Beijing: Foreign Language Teaching and Research Press.

Gill, R. (1985). Mastering English literature (p. 36). Houndmills, Basingstoke, Hampshire and London: Macmillan Education Ltd.. Hornby, A. S. (2009). Advanced learners' English-Chinese dictionary (7th ed.). Beijing: The Commercial Press \& Oxford University Press.

Maud, R. (1963). Entrances to Dylan Thomas’ poetry (p. 70). Pittsburgh: University of Pittsburgh Press.

Perrine, L. (1987). Sound and sense: An introduction to poetry (p. 10). Chicago: Harcourt Brace Jovanovich, Inc..

Thomas, D. (2003). The poems of Dylan Thomas (p. 90). D. Jones (Ed.). New York: W. W. Norton \& Company.

\section{Appendix: The Force That Through the Green Fuse}

Dylan Thomas [1914-1953] 
The force that through the green fuse drives the flower

Drives my green age; that blasts the roots of trees

Is my destroyer.

And I am dumb to tell the crooked rose

My youth is bent by the same wintry fever.

The force that drives the water through the rocks

Drives my red blood; that dries the mouthing streams

Turns mine to wax.

And I am dumb to mouth unto my veins

How at the mountain spring the same mouth sucks.

The hand that whirls the water in the pool

Stirs the quicksand; that ropes the blowing wind

Hauls my shroud sail.

And I am dumb to tell the hanging man

How my clay is made the hangman's lime.

The lips of time leech to the fountain head;

Love drips and gathers, but the fallen blood

Shall calm her sores.

And I am dumb to tell a weather's wind

How time has ticked a heaven round the stars.

And I am dumb to tell the lover's tomb

How at my sheet goes the same crooked worm. 